\title{
MORBIDADE EM CRECHE DE BRASILIA ESTUDO LONGITUDINAL DE INCIDENCIA DE ENFERMIDADES NO ANO DE 1977
}

Ana Maria Low * Maurício Gomes Pereira**

Low, A. M. \& Pereira, M. G. Morbidade em creche de Brasillia: estudo longitudinal de incidência de enfermidades no ano de 1977. Rev. Saúde públ., S. Paulo, 14:454-61, 1980.

Resumo: Foi feito estudo longitudinal de morbidade em creche de Brasilia (Brasil) freqüentada por criancas com bom estado nutricional. Foram admitidas na creche durante o ano de 1977 o total de 67 criancas ( 34 do sexo masculino e 33 do sexo feminino), com idade entre 3 e 21 meses. Infecçóes de vias aéreas superiores $(25,4 \%)$, diarréia $(23,6 \%)$ e febre não esclarecida $(18,4 \%)$ representaram dois terços dos diagnósticos. A seguir, em ordem de freqüência, apareceram conjuntivite $(15,5 \%)$, viroses da infância $(7,9 \%)$, doenças de pele $(3,8 \%)$, pequenos acidentes $(\mathrm{B} 2,6 \%)$, hepatite $(2,6 \%)$ e meningococcemia $(0,3 \%)$. Houve um total de 343 episódios agudos, dando uma taxa de incidência de 14 enfermidades por criança por ano, independente de sexo e idade.

Unitermos: Morbidade, Brasilia, Brasil. Epidemiologia, métodos. Creches.

\section{INTRODITAO}

$O$ conhecimento da morbidade na infáncia tem sido preocupação constante de pediatras, nutricionistas e especialistas de saúde pública. Este interesse é maior nos primeiros anos de vida, periodo de grande vulnerabilidade da criança a condições adversas do meio ambiente. É nesta época que as doenças infecciosas e nutricionais assumem maior gravidade, interferindo, muitas vezes, no crescimento físico e no desenvolvimento mental, sendo responsáveis pela maioria dos óbitos em regióes em desenvolvimento $1,9,1 \%$. Diversos métodos existem para medir a freqüència de doenças em grupos de individuos $\bar{~} \mathrm{O}$ seguimento longitudinal através de exames periódicos, a curtos intervalos, permite o conhecimento da morbidade com alto grau de precisão. $\mathrm{O}$ fato de um dos autores deste trabalho k: ter exercido atividades de pediatra junto a creche, deu-nos a possibilidade de observação continuada de um mesmo grupo de crianças, por um mesmo observador, aliado a facilidades de diagnóstico clínico e labo-

\footnotetext{
* Consultora de Saúde da urganizaçâo Mundial de Ẽucação Pré-escolar (OMEP) - 70000 Brasilia, DF - Brasil.

** Do Departamento de Medicina Geral e Comu nitária da Universidade de Brasilia - Caixa Postal 15.2922 - 70000 - Brasilia, DF - Brasil.

*** Ana Maria Low, pediatra da creche da Universidade de Brasilia, em 1977.
} 
LOW, A. M. \& PEREIRA, M. G. Morbidade eni creche de Brasilia: estudo longitudinal de incidència de enfermidades no ano de 1977. Rev. Saude públ., S. Paulo, 14:454:61. 1980.

ratorial em casus de enfermidade. O presente trabalho objetiva descrever a morbidade na creche da Universidade de Brasilia (UnB), no ano de 1977.

\section{FUNCIONAMENTO DA CHECHE}

A creche da UnB, localizada no campus universitário, em pavilhão isolado e ladeado por ampla área verde, possuia instalaçóes amplas e arejadas, ainda que provisórias * Foi feita com capacidade para 40 crianças, filhos de professores, funcionários e alunos da universidade. $O$ quadro de pessoal compunha-se de 19 funcionários. A pediatra permanecia na creche pela manhã e ocasionalmente à tarde quando era solicitada. Os funcionários foram selecionados de um grupo que participou de um curso de treinamento onde foram abordados problemas de higiene e puericultura. Mensalmente esses funcionários participavam de reunióes com a pediatra; a cada semestre submetianı-se a exames de cultura de orofaringe e parasitológico de fezes, e, anualmente, faziam exame clinico geral e abreugrafia.

$\mathrm{Na}$ cumsulta de admissão, as crianças foram submetidas a exame médico, sendo os dados de antropometria, de antecedentes patológicos e de vacinas anotados no prontuário. Nessa ocasião foram feitos exames parasitológicos de fezes. Mensalmente, as crianças foram revistas pela pediatra em exame clinico semelhante ao de admissão.

\section{MATERIAL E MÉTODOS}

Foram admitidas 67 crianças na creche durante o ano, 34 do sexo masculino e 33 do sexo feminino, com idade variando entre 3 e 21 meses na admissão. Em momento algum, porém, a creche comportou mais de 40) crianças.
A tomada de peso e altura toi padronzada e feita sempre pela mesma pessoa. As anotações de morbidade, feitas pela pediatra, já visavam determinar o padrāo de doenças nessa população. Cada episódio de doença foi registrado com um diagnóstico apenas, aquele considerado como a doença básica. Os diagnósticos secundários não foram considerados na análise.

\section{RUSULTADOS}

Infecçoes de vias aereas superiores (resfrjados, amigdalites, rinites e otites), diarréias e febre não esclarecida representaram $2 / 3$ dos diagnósticos feitos na creche durante () ano (Tabela 1). O número de casos de conjuntivite foi elevado, ocupando - 4" lugar en freqüència, vindo a seguir as viroses proprias da infancia. Sarampo, rubéola e cachumba ocorreram em forma epidèmica. Isto é mostrado na Fig. 1, unde também estão representados os casos de hepatite ocorridos no final do ano. As demais viroses da infancia -- varicela, roséola infantum e eritema infeccioso ocorreram como casos isolados. Afecçós cutâneas (impetigo e alergia) e pequenos acidentes, na maioria quedas, ocorreram poucas vezes. Houve um óbito por meningococcemia. Observou-se en Brasilia, na ocasiāo, taxas hiperendêmicas de meningite meningocócica que se seguiram ao surto epidêmico de 1974-1975**. Culturas de orofaringe das crianças e do pessoal da creche revelaram-se negativas. A fonte provável de contágio foi a empregada da família da criança, recém admitida na casa. cuja cultura foi positiva para meningococo. Não houve caso secundário de doença meningocócica na creche. Além deste óbito, as outras doenças agudas não deixaram seqüela e nenhuha doença crónica incapacitante foi diagnosticada no periodo. Não

\footnotetext{
* Construída em madeira, a creche foi fechada, em 1978, para funcionamentu futuro, em prédio definitivo, ainda nāo construido na época da apresentação deste trabalho.

* Dados inéditos - Secretaria de Saude do Distrito Federal.
} 
LOW, A. M. \& PEREIRA, M. G. Morbidade em creche de Brasília: estudo longitudinal de incidência de enfermidades no ano de 1977. Rev. Saúde públ., S. Paulo, 14:454:61, 1980.

TABELA 1

Morbidade na creche da Universidade de Brasilia, em 1977.

\begin{tabular}{lcc}
\hline & \multicolumn{2}{c}{ Frequiencia } \\
& Patologia & No \\
\hline Respiratória & 87 & 25,40 \\
Gastrointestinal & 81 & 23,60 \\
Febre não esclarecida & 63 & 18,40 \\
Conjuntivite & 53 & 15,50 \\
Viroses da Infância & 27 & 7,90 \\
Cutânea & 13 & 3,80 \\
Acidentes & 9 & 2,60 \\
Hepatites & 9 & 2,60 \\
Meningococcemia & 1 & 0,30 \\
\hline Total & 343 & 100,00 \\
\hline
\end{tabular}

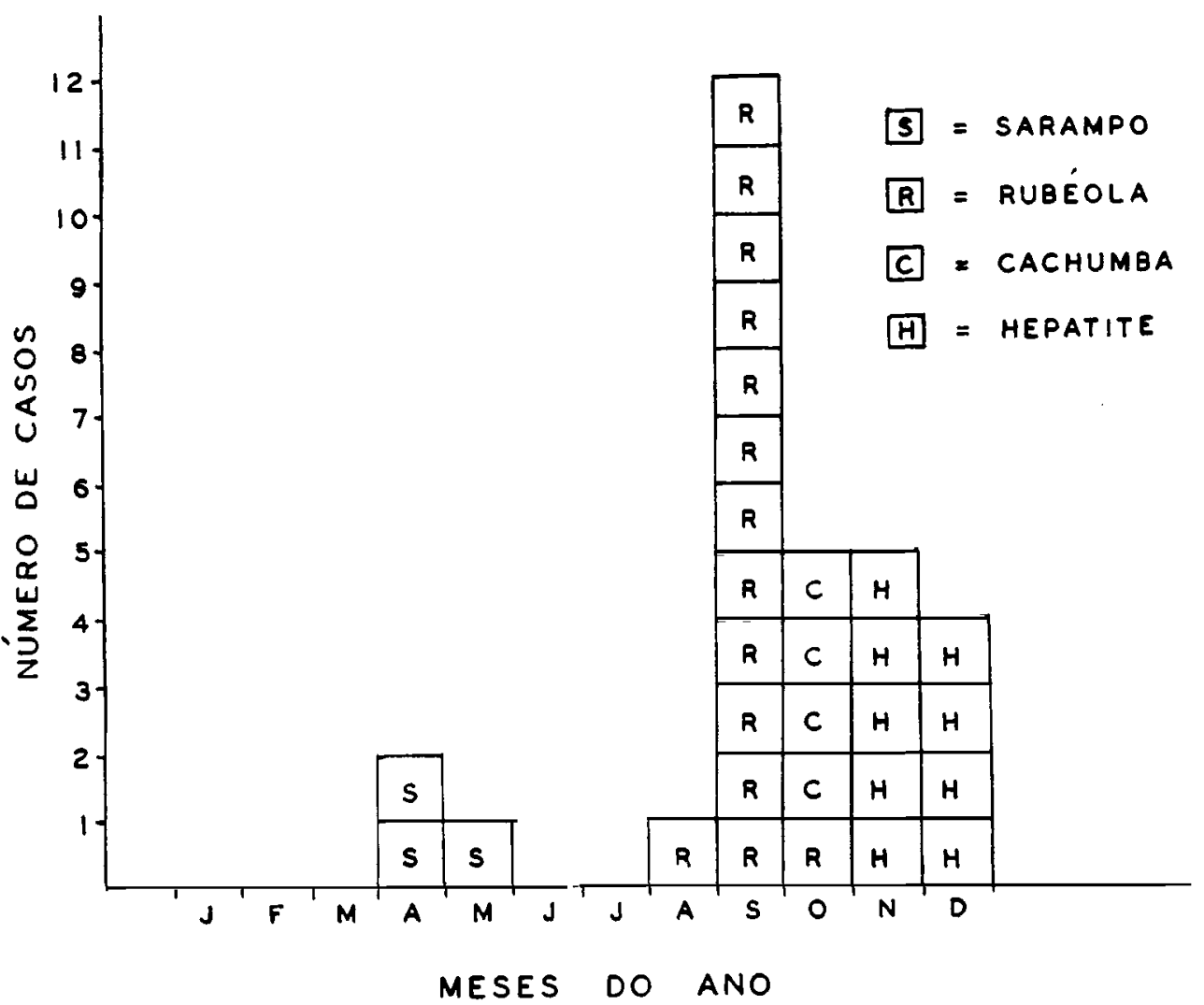

Fig. 1 -- Casos de sarampo, rubéolia, cachumba e hepatite infecciosa na creche da Universidade de Brasilia, distribuídos pur mês de ocorrência, 1977. 
LOW, A. M. \& PEREIRA, M. G. Morbidade em creche de Brasillia: estudo longitudinal de incidência de enfermidades no ano de 1977. Rev. Saúde públ., S. Paulo, 14:454:61, 1980.

foram levados em conta distúrbios emocionais e de conduta.

Em relação à época do ano, além das doenças representadas na Fig. 1, houve, também, um aumento de casos de infecção respiratória no mês de março e de conjuntivite e diarréia no mês de agosto. Isto pode estar relacionado a dois fatores atuando simultaneamente. De um lado, março e agosto são meses de reinício de atividades na creche quando um grupo de crianças com baixa imunidade são colocadas juntas, facilitando a transmissão de enfermidades. Por outro lado, o aumento de freqüência destas infecções nestes meses pode estar diretamente relacionado às condições climáticas da cidade que se caracterizam basicamente por duas estações: período das chuvas, de outubro a abril, em que a umidade relativa do ar se mantém elevada, e período da seca, quando a umidade permanece baixa chegando a valores inferiores a $20 \%$ no meio do ano.

A morbidade não esteve relacionada ao sexo da criança e apenas os acidentes e os casos de hepatite guardaram relação com a idade, ocorrendo ambos exclusivamente no segundo ano de vida. Não houve associação entre o número de enfermidades agudas e faixa etária. A Tabela 2 mostra que, independente da faixa etária, uma criança mantida na creche oito horas por dia, durante todo 0 ano, apresentaria 14 doenças agudas no periodo. $O$ coeficiente de incidência de doenças foi calculado usando-se o número de pessoas-ano de observação ${ }^{5}$, tomando-se em conta que o período de observação não foi o mesmo para todas as crianças. Uma análise idèntica, com os grupos etários classificados por semestre, mostrou resultados semelhantes aos apresentados, exceto, uma leve tendência a menor morbidade nas crianças mais velhas.

Deve-se notar que as crianças admitidas na creche tinham bom estado nutricional (Fig. 2) e conservaram estas características pelo tempo em que lá estiveram. Como era de se esperar em crianças de bom nivel sócio-econômico, as medidas antropométricas da maioria situavam-se em torno da média esperada para a idade, com a presença de algumas crianças francamente obesas e nenhuma subnutrida. A única com peso inferior a $90 \%$ do esperado pelo padrão Harvard 8 apresentava proporcionalidade peso-altura e bom estado nutricional.

Além da morbidade surgida espontaneamente, exames parasitológicos de fezes foram feitos na época de admissão das crianças na creche e estes dados não estão computados na Tabela 1 . De 40 exames efetuados no mês de março, 21 foram positivos sendo um para Hymenolepsis nana, três para Entameba coli e 17 para Giardia lamblia, mostrando a grande extensão da infestação por giardia em crianças pequenas.

\section{DISCUSSAO}

O coeficiente de incidência de doenças na creche da UnB apontou uma média de 14 enfermidades agudas por criança que tivesse frequientado a creche durante todo 0 ano, 5 dias na semana, 8 horas por dia. Este resultado se aproxima do coeficiente de morbidade em crianças desnutridas, onde se observa freqüentemente o binômio desnutrição-infecção. Assim, na Guatemala, um estudo longitudinal envolvendo crianças de baixo nivel sócio-econômico, seguidas do nascimento até a idade de 3 anos, mostrou uma freqüência média de 18 enfermidades infecciosas por crianças e por ano ${ }^{6}$. No entanto, na creche de Brasilia, casos de desnutrição não foram observados. As crianças provêm de famílias da classe média com estado nutricional adequado como foi mostrado na Fig. 2.

A taxa de morbidade na creche é alta se comparada a de estudos feitos em grupos presumivelmente com bom estado nutricional. Em crianças menores de um ano de idade na Bélgica, na Inglaterra e nos Estados Unidos, constatou-se de 3 a 4 en- 
LOW, A. M. \& PEREIRA, M. G. Morbidade em creche de Brasília: estudo longitudinal de incidência de enfermidades no ano de 1977. Rev. Saúde públ., S. Paulo, 14:454:61, 1980.

TA BELA 2

Análise quantitativa da morbidade na creche da Universidade de Brasília por faixa etária, 1977.

\begin{tabular}{cccc}
$\begin{array}{c}\text { Grupo etário } \\
\text { (meses) }\end{array}$ & $\begin{array}{c}\text { Casos de } \\
\text { enfermidade }\end{array}$ & $\begin{array}{c}\text { Pessoas-ano } \\
\text { de observação }\end{array}$ & $\begin{array}{c}\text { Casos de enfermida- } \\
\text { de por uma pessoa- } \\
\text {-ano de observaçõo }\end{array}$ \\
\hline $\begin{array}{c}\text { menor de } 12 \\
12 \text { e mais }\end{array}$ & $\mathbf{9 2}$ & 6.16 & $14.94 *$ \\
Total & 343 & 18.00 & $13.94 *$ \\
\hline
\end{tabular}

Pessoas-ano de observação $=N^{\circ}$ de meses freqüentados por todas as crianças desta faixa etária dividido por 12.

* $\mathrm{X}:=0.035: \eta>0.05$ (nåo significativo)

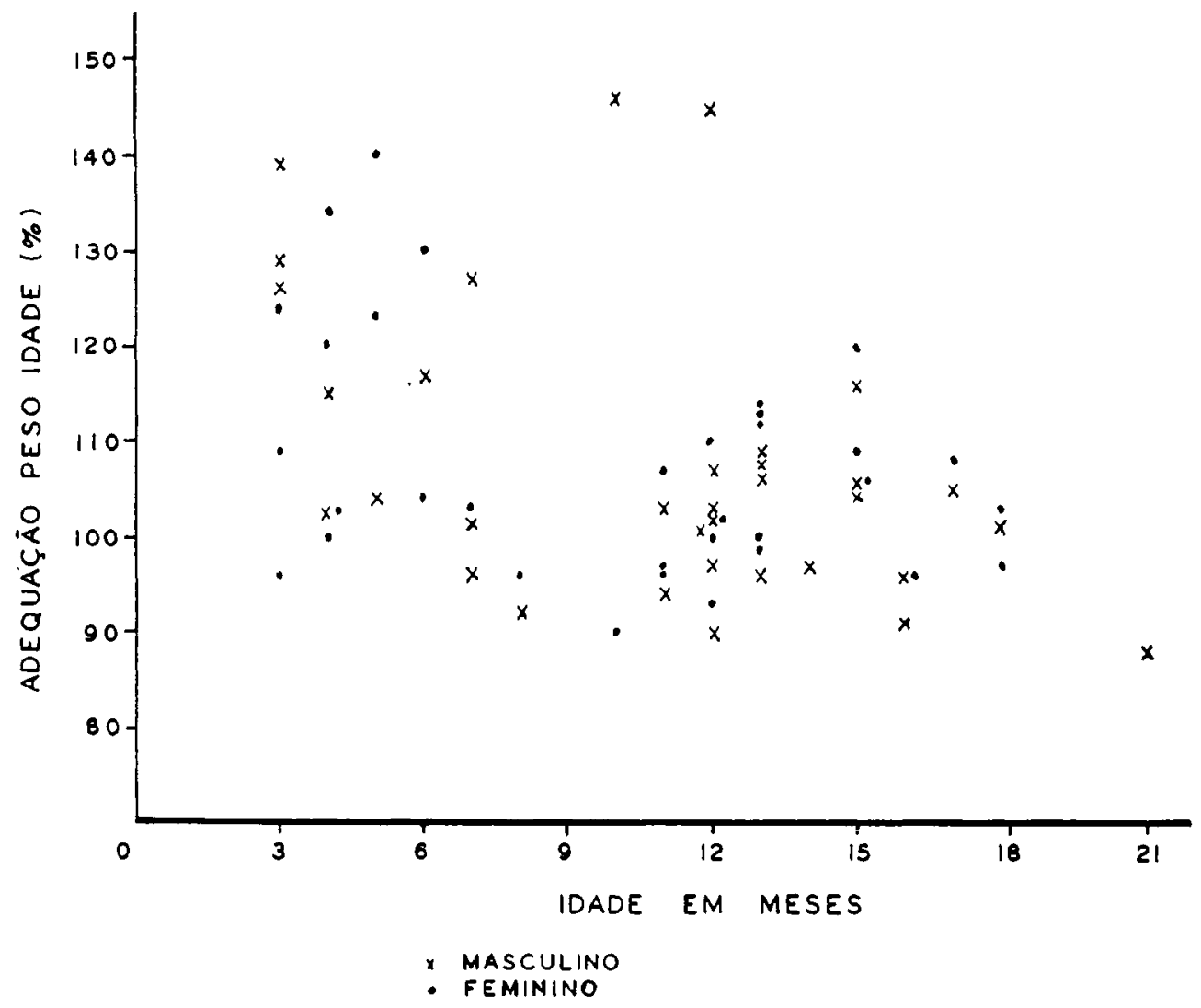

Fig. 2 - Peso das crianças na época de admissão na creche. expresso em percentagem do peso médio esperado para a idade (referência: percentil 50 de Harvard ${ }^{8}$ ): Brasilia, 1977. 
LOW, A. M. \& PEReirA, M. G. Morbidade em creche de Brasilia: estudo longitudinal de incidência de enfermidades no ano de 1977. Rev. Saúde públ., S. Paulo, 14:454:61, 1980.

fermidades anuais ${ }^{1}$. Em crianças peruanas menores de 5 anos, da classe média, foram relatados 7 episódios agudos por ano ${ }^{3}$. Parte das diferenças observadas entre estes dados e os da creche de Brasília podem ser devidos a questões metodológicas, já que os trabalhos citados estão baseados em interrogatórios a intervalos nunca inferiores a um mês, dando oportunidade a que doenças leves não fossem anotadas. $\mathrm{Na}$ creche da UnB, ao contrário, por ter sido feito um estudo prospectivo, com observação diária das crianças e identificação sistemática das causas de absenteísmo, podese admitir que a morbidade observada na creche esteja bem mais próxima da morbidade efetivamente experimentada pelas crianças. No entanto, a própria creche pode ter-se constituído no principal fator responsável pelo grande número de doenças; a simples reunião de crianças com baixa resistência imunológica - devida a pouca idade - num mesmo ambiente, oferece condições ideais para transmissão de doenças contagiosas. Essa hipótese, para ser testada cientificamente, necessitaria da comparação das taxas de morbidade na creche com as de um grupo de crianças com caracteristicas semelhantes mas que não estivessem freqüentando creche ou outras instituições de semi-internato, grupo este que não foi constituido na ocasião.

A quase totalidade das doenças observadas na creche de Brasilia foi de natureza infecciosa. As enfermidades mais encontradas - infecções respiratórias e digestivas - foram também as mais comuns na prática pediátrica de outros autores ${ }^{1,3,6}$. Assim, diminuir o coeficiente de morbidade em crianças pequenas inclui predominantemente o controle de doenças infecciosas. No entanto, os métodos de controle dessas infecções, principalmente em creches, são apenas parcialmente eficazes. Além de medidas de higiene do meio ambiente visando erradicar os agentes de enfermidades tais como limpeza, desinfecção, combate a vetores entre outros - duas medidas de prevenção secundária foram enfatizadas: diagnóstico precoce e afastamento de doentes pelo período de transmissibilidade da enfermidade. A aplicação dessas duas medidas sempre envolve dificuldades práticas. As encontradas na presente pesquisa são comentadas a seguir:

1 - Diagnóstico precoce: procurou-se evitar focos de infecçōes através de esclarecimento dos pais para que não trouxessem crianças doentes para a creche. O pessoal da creche foi preparado e estimulado a recusar suspeitos de enfermidades, à entrada, pela manhã. Um berçário de observação era usado para isolamento imediato de alguma criança, ao primeiro sinal de enfermidade, quando isto fosse observado durante a sua permanência na creche, enquanto aguardava a chegada dos pais. Em muitos casos notou-se omissão de informaçōes dos pais com respeito ao estado de saúde dos filhos. Talvez a participação ativa dos responsáveis pela criança, evitando trazer à creche crianças doentes ou mesmo aquelas recentemente expostas à infecções de algum outro familiar, pudesse diminuir os níveis de infecção observados.

\section{2 - Período de afastamento: o critério} para a admissão após a enfermidade dependeu da natureza de cada caso. Em casos de diarréia, infecçōes respiratórias, febre não esclarecida e conjuntivite providenciouse afastamento dos pacientes durante todo o período sintomático ou então após $48 \mathrm{~h}$ de uso de antibiótico. Nas doenças em que o período de transmissibilidade é conhecido, como nas viroses próprias da infância, afastou-se a criança da creche pelo restante do periodo de transmissibilidade, a partir de normas da American Public Health Association ${ }^{2}$. Na maioria dos casos, este procedimento não evita o aparecimento de casos secundários. Quando se inicia 0 quadro clínico, a criança já esteve eliminando germes para o meio ambiente por algum tempo e transmitiu a doença para seus contactos. 
LOW, A. M. \& PEREIRA, M. G. Morbidade em creche de Brasilia: estudo longitudinal de incidência de enfermidađes no ano de 1977. Rev. Saúde públ., S. Paulo, 14:454:61, 1980.

Um registro de vacinaçōes foi mantido atualizado para cada criança com respeito às imunizações de rotina, ou seja, contra difteria, tétano, coqueluche, pólio, sarampo, varíola e tuberculose. Houve, no entanto, 3 casos de sarampo, sendo apenas um em criança não vacinada, por contar 5 meses de idade. As duas outras tinham sido vacinadas aos 12 meses de idade. Isto permite pensar no uso de vacinas antigenicamente deficientes, talvez por falhas no armazenamento ou transporte das mesmas até Brasília. Devido à gravidade da doença e à existência de uma vacina comprovadamente eficiente, estes aspectos devem ser melhor explorados.

As vacinas contra rubéola e cachumba, apesar de disponíveis em farmácias no ano de 1977, não foram usadas em nenhuma das crianças na creche. Houve epidemias destas duas enfermidades, sendo que a de rubéola ocorreu com grande número de casos, certamente ainda maior do que o expresso na Fig. 1, pois lá não estão assinaladas as infecções inaparentes, sempre presentes em epidemias dessas enfermidades. O afastamento das crianças com rubéola teve efeito limitado no controle da infecção, provavelmente pelo mesmo motivo antes levantado, ou seja, a eliminação do virus se iniciar antes do primeiro sinal clínico da doença. Ocorreu uma epidemia de hepatite no final do ano, com 6 casos clínicos e 3 subclínicos conhecidos, o que motivou o fechamento da creche 2 semanas antes do previsto. Este assunto será objeto de outro estudo.

Em conclusão, pode-se afirmar que a creche da UnB, sem finalidade lucrativa, buscou ser um modelo de funcionamento. Pode-se admitir que as medidas adotadas e descritas no texto tenham prevenido alguns casos de doenças ou mesmo epidemias. Porém, como os resultados apresentados indicaram, as medidas não foram suficientes para manter um baixo indice de morbidade.

RSPUB9/523

Low, A. M. \& Pereira, M. G. IMorbidity in a Brasilia day care center: a longitudinal study of disease incidence in 1977./ Rev. Saúde públ., S. Paulo, 14: 454-61, 1980 .

ABSTRACT: A longitudinal morbidity study was carried out in a day carc center in Brasilia (Brazil) on a sample of 67 (34 male and 33 female, 3 to 21 months of age) well-fed children from middle-class families. A pediatrician was on duty daily in the center. The incidence of disease was: upper respiratory, $25.4 \%$; diarrhea, $23.6 \%$; and undetermined fever, $18.4 \%$. These represented $2 / 3$ of the diagnoses. The other diseases found (and here listed in order of frequency) were: conjunctivitis, $15.5 \%$; childhood infections, $7.9 \%$; skin diseases, $3.8 \%$; accidents, $2.6 \%$; hepatitis, $2.6 \%$; and meningitis, $0.3 \%$. There were a total of 343 acute illnesses, giving a mean incidence rate of 14 illnesses per child per year, independent of sex and age. Perhaps the incidence of illnesses would have been lower if the children had not been attending the center, a natural factor in the dissemination of communicable diseases.

UNITERMS: Morbidity, Brasilia, Brazil. Epidemiology, methods. Child day care centers. 
LOW, A. M. \& PEREIRA, M. G. Morbidade em creche de Brasília: estudo longitudinal de incidência de enfermidades no ano de 1977. Rev. Saúde públ., S. Paulo, 14:454:61, 1980.

\section{REFERENCIAS BIBLIOGRAFICAS}

1. ASIEL, M. La morbidité pendant la première année de vie. Arch. belg. Med. soc. 4:357-76. 1961.

2. BENENSON, A. S., ed. Control of communicable diseases in man. 12th ed. Washington, American Public Health Association, 1975.

3. CASTANEDA, C. R. et al. El nivel de salud del niño en Trujillo, Peru: encuesta de morbilidad en niños menores de cinco años. Bol. Ofic. sanit. panamer., $81: 157-71, \quad 1978$.

4. CIARI JR, C. \& SIQUEIRA, A. A. F. de Problemas de saúde materno-infantil no Brasil. In: Paretta, J. M. M. et al. Saúde da comunidade. São Paulo, Ed. McGraw-Hill do Brasil, 1976 p. 203-23.

5. FORATTINI, O. P. Epidemiologia geral. São Paulo, Ed. Edgard Blucher /Ed. USP. 1976. p. 79 .
6. MATA, L. J, et al. Breast-feeding, weaning and the diarrhoeal syndrome in a Guatemalan Indian village. In: Acute diarrhea in childhood. Amsterdan. 1976. p. 311-30. (Ciba Found. Symp, r. 42).

7. MACMAHON, B. \& PUGH, T. F. Epiatmiology: principles and methods. Boston, Little Brown. 1970. p. 57-102.

8. NELSON, W. E. et al, Tratado de pediatria. 6th ed. Barcelona, Salvat. 1974.

9. PUFFER. R. R. \& SERRANO, C. V. Patterns of mortality in childhood. Washington, Pan American Fealth Organization. 1973. (PAHO - Scient. publ. 262).

10. SUSSER, M. W. \& WATSON, W. Sociology in medicine. New York, Oxford University Press, 1971 cap. 1 e 10.

Recebido para publicação em 09/04/1980 Aprovado para publicação em 23/06/1980 